\title{
PENATAAN RUANG KELAS YANG SESUAI DENGAN AKTIVITAS BELAJAR Kasus: PAUD Kuncup Matahari dan PG/RA Mutiara Bhima Sakti Sidoarjo
}

\author{
Triandriani M., Noviani S., Ema Yunita T. \\ Jurusan Arsitektur Universitas Brawijaya \\ Email: anisajid@gmail.com
}

\begin{abstract}
ABSTRAK
Permasalahan utama PG/RA Mutiara Bhima Sakti dan PAUD Kuncup Matahari terkait ruang kelasnya adalah bagaimana mengoptimalkan sumber daya ruang yang tersedia agar dapat menjadi wadah yang akomodatif bagi kegiatan pembelajaran. Hal ini merupakan salah satu faktor yang mendukung keberhasilan program pembelajaran. Tujuan kegiatan ini adalah untuk menyediakan ruang yang sesuai dengan kegiatan pembelajaran. PG/RA Mutiara Bhima hanya memiliki 1 ruang kelas permanen, sedangkan 1 ruang disekat untuk 2 kelas dan juga digunakan untuk ruang pertemuan. Daya tampung kelas PAUD Kuncup Matahari terlalu kecil untuk jumlah siswa yang diwadahi. Dari hasil analisis dan sesuai dengan program pembelajaran sistem BCCT, disusun ruang menurut sentra-sentra, yaitu: sentra dramatik, sentra bahan alam, sentra balok, sentra persiapan, dan lain-lain. Zonazona ini disusun dengan memanfaatkan ruang yang tersedia secara optimal. Satu zona dapat digunakan oleh beberapa kelas secara bersama-sama, atau digunakan dalam waktu yang berbeda. Sifat ruangnya fleksibel, sehingga dalam waktu dan kegiatan yang berbeda, ruang tersebut dapat diubah tatanannya untuk kegiatan dengan sifat zona yang berbeda.
\end{abstract}

Kata kunci: penataan, ruang kelas, anak-anak

\begin{abstract}
The main problem of PG/RA Mutiara Bhima Sakti and PAUD Kuncup Matahari's classroom design is how to optimize the available space-resources to accomodate learning acitivities. This could be a supporting factor to success learning program. This research aim to find the suitable classroom model for PG/RA Mutiara Bhima Sakti and $P A U D$ Kuncup Matahari by studying of space-use and learning program. PG/RA Mutiara Bhima have only 1 permanent classroom, while another classroom was divided into 2 classrooms using non-permanent divider. PAUD Kuncup Matahari's classroom was too small to accomodate all the students. From the result of the analysis and according to BCCT program (as the learning program used by those two prescools), we arrange classroom into centers: natural, dramatic, preparation, block, etc. These centres was arranged by utilize space-resources optimizely. One centre colud be used by one class or more, in the same time or in different time. The classrooms was designed flexible. They can be used for different activities by changing their interior arrangement.
\end{abstract}

Kata kunci: arrangement, classroom, children 


\section{Pendahuluan}

PG/RA Mutiara Bhima Sakti dan PAUD kuncup Matahari merupakan wahana pendidikan anak usia dini. Fasilitas PG/RA Mutiara Bhima Sakti terdiri dari 1 ruang kelas permanen, 2 ruang kelas semi-permanen area bermain outdoor, area terbuka untuk upacara atau olah raga, area terbuka hijau, dan kamar mandi /wc. Potensi ruang untuk pengembangan sangat besar karena lahan yang tersedia masih sangat luas. Berbeda dengan PAUD Kuncup Matahari yang terletak di area perumahan, lahan yang dimilikinya sempit. Tidak ada ruang terbuka hijau, dan ukuran kelas hanya $3 \mathrm{~m} \times 4 \mathrm{~m}$ untuk menampung 20-25 anak. Terdapat 1 ruang yang cukup besar di bagian depan sebagai area penerima dan 1 area berukuran $3 \mathrm{~m} \times 3 \mathrm{~m}$ untuk tempat bermain.

Kondisi umum kedua lembaga pendidikan ini adalah sbb:

1. Ruang ditata secara klasikal, misalnya dengan menempatkan kursi-kursi menghadap ke arah papan tulis, atau ditata secara berkelompok. Hal ini menyebabkan suasana ruang kelas terkesan formal. Model penataan semacam ini tidak tepat untuk metode pembelajaran, yang menghendaki interaksi aktif antara guru-murid dan antara murid-murid. Eksplorasi guru secara individual pada tiap murid tidak berjalan optimal.

2. Alat-alat peraga dan permainan anak-anak disimpan dalam rak, tetapi tidak dikelompokkan menurut jenisnya. Guru yang menyiapkan dan membereskan mainan. Pengelompokan sesuai jenis dan penempatan di tempat yang tetap akan memudahkan anak-anak membereskan mainan.

3. Pemajangan hasil karya anak-anak bersifat menyebar, tidak dikelompokkan menurut jenisnya.

4. Posisi poster dan gambar yang ditempel di dinding terlalu tinggi sehingga tidak terjangkau oleh pandangan anak-anak.

5. Tidak ada area khusus untuk memasang gambar atau hasil karya anak-anak di dinding, sehingga hasil karya anak-anak ditempel sembarangan di dinding.

6. Sebagian besar asesoris ruangan tidak dapat dipakai untuk alat bantu belajar.

7. Tidak dikenal pembedaan zona kegiatan tenang dan kegiatan aktif. Pembedaan zona ini diperlukan untuk menunjang efektivitas kegiatan belajar, memudahkan anakanak memahami tempat sehingga dapat menyesuaikan sikap dan perilaku mereka, serta menumbuhkan kedisiplinan.

Kondisi khusus ruang-ruang PG/RA Mutiara Bhima Sakti adalah sbb:

1. Ruang kelas PG dan TK B merupakan ruang kelas semi-permanen sekaligus ruang pertemuan. Penyekat kedua ruang tersebut adalah papan penyekat non permanen. Sisi timurnya menghadap ke teras dan halaman (lihat gambar 1 dan 2). Total luas ruang PG dan TK B adalah 3,5m x 7m. Keduanya bukan ruang yang didesain untuk ruang kelas. Permasalahan-permasalahan yang cukup mengganggu kegiatan belajarmengajar pada ruang ini antara lain:

a. Adanya gangguan audio-visual dari ruang-ruang yang bersebelahan. Hal ini ini memancing aktivitas gerak anak-anak sehingga konsentrasi belajar menjadi terganggu.

b. Perletakan rak untuk menyimpan peralatan belajar, papan tulis, meja-kursi guru, meja-kursi anak-anak, papan tulis, dan fasilitas lainnya kurang efektif. Hal ini terlihat misalnya, pada saat guru mengajar, ada anak-anak yang mengambil mainan atau alat-alat tulisnya di rak, kemudian asyik bermain sendiri. 
c. Alat bermain dan belajar tidak tersimpan rapi karena kurangya rak dan lemari penyimpan.

2. Ruang terbuka hijau di sekolah ini cukup luas, namun belum terolah dan tidak terawat. Ruang ini sangat potensial untuk dimanfaatkan dalam kegiatan belajar, terutama terkait tema pembelajaran mengenai pengenalan lingkungan (alam).

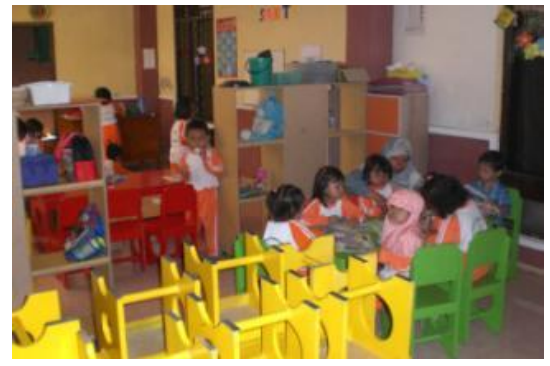

Gb 1. Rak/loker sebagai Pembatas Ruang Kelas

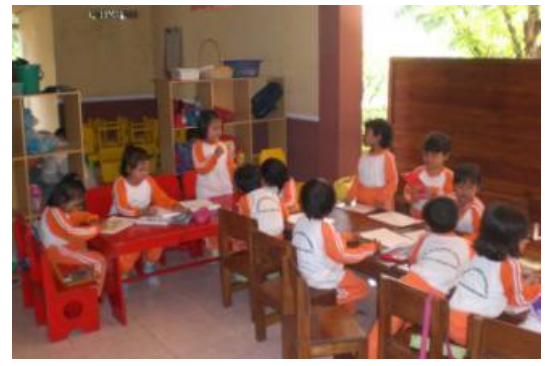

Gb 2. Sekat Kayu/papan Pembatas Ruang Kelas

Kondisi khusus PAUD Kuncup Matahari adalah sbb:

1. Kurangnya ruang terbuka sebagai tempat bermain, olah raga, dan upacara.

2. Letak kamar mandi/wc dan pantry di dalam salah satu kelas sehingga kegiatan di ruang tersebut terganggu jika ada yang hendak ke $\mathrm{km} / \mathrm{wc}$ atau pantry.

3. Ruang kelas terlalu sempit untuk menampung seluruh murid. Ukurannya hanya $3 \mathrm{mx} 4 \mathrm{~m}$ untuk 20-25 anak.

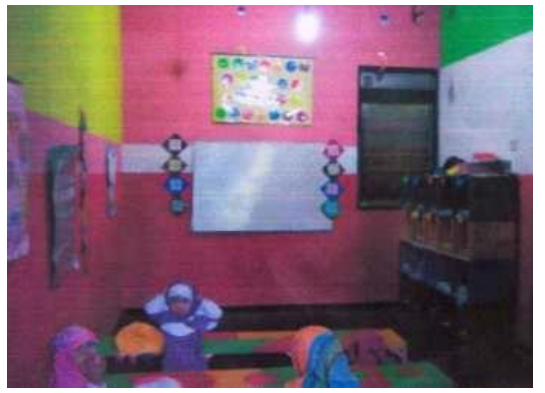

Gambar 3. Letak Gambar dan Poster di Dinding 'menyebar' dan Terlalu Tinggi

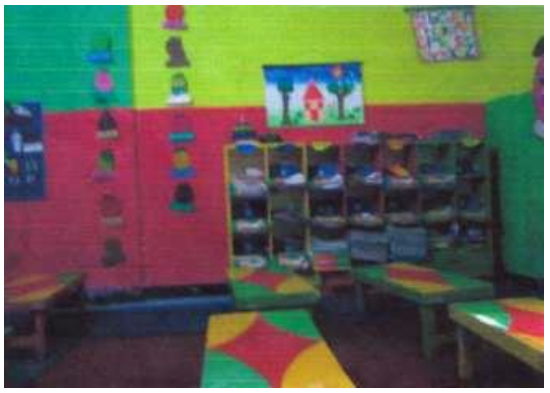

Gambar 4. Jarak antara Rak/loker dengan Kursi Memudahkan Mengambil dan Menyimpan Peralatan

Keterbatasan fasilitas PG/RA Mutiara Bhima Sakti dan PAUD Kuncup Matahari perlu disiasati agar dapat diciptakan ruang kelas yang kondusif untuk belajar. Potensi ruang luar dapat dikembangkan unuk mendukung kegiatan belajar dan menutupi kekuarangan atas keterbatasan luasan ruang kelas, khususnya pada PG/RA Mutiara Bhima Sakti. Warna, material, jenis, bentuk, dan penataan perabot merupakan unsur-unsur desain yang mempengaruhi terciptanya ruang yang kondusif bagi kegiatan belajar.

\section{Bahan dan Metode}

Dalam rangka mengembangkan potensi kecerdasan anak, khususnya anak-anak usia 
dini, menurut Direktorat Pendidikan Anak Usia Dini (2002:7), prinsip-prinsip penyelanggaraan pendidikan anak usia dini antara lain adalah:

1. Berorientasi pada kebutuhan anak (intelektual, bahasa, motorik, dan sosioemosional)

2. Belajar sambil bermain

3. Merangsang munculnya kreativitas dan inovasi

4. Menyediakan lingkungan belajar yang mendukung proses belajar

5. Mengembangkan kecakapan anak agar mereka mampu menolong diri sendiri, mandiri, bersosialisasi, dan bertanggungjawab serta disiplin.

6. Menggunakan berbagai sumber dan media belajar yang ada di lingkungan sekitarnya

7. Pembelajaran dilakukan secara berulang-ulang, mulai dari yang sederhana

8. Rangsangan pendidikan bersifat menyeluruh

Konsentrasi belajar pada saat proses pembelajaran dapat ditingkatkan apabila (Satyawadaningtyas, 2009):

1. Terdapat jarak tertentu antara zona aktif dan zona tenang.

2. Terdapat pembatas vertikal yang mencegah tembusnya pandangan dan gerakan ke luar ruang kelas.

3. Penataan perabot memungkinkan terbentuknya fokus orientasi ke arah yang dikehendaki. Penataan ini dapat diubah-ubah sesuai kebutuhan.

4. Penataan dan desain perabot diatur sedemikian sehingga dapat menghalangi gerakan dan pandangan anak-anak ke tempat-tempat atau area-area yang tidak dikehendaki

Sesuai dengan konsep dan metode pembelajaran anak-anak, maka idealnya, ruang kelas ditata menurut jenis-jenis kegiatan yang dilakukan. Menurut Olds (2001; dan 2006), zona-zona yang terdapat dalam ruang kelas anak-anak usia playgroup dan taman kanakkanak antara lain:

1. Zona penerima (entry zone) : tempat anak-anak diantar dan dijemput, dan tempat melepas dan menyimpan jaket dan alas kaki.

2. Zona messy : digunakan untuk kegiatan yang berhubungan dengan air, cat, tanah liat, memasak dan menata makanan, dan sebagainya.

3. Zona tenang: tempat melakukan kegiatan yang memerlukan konsentrasi tinggi.

4. Zona aktif: tempat bermain aktif

5. Zona dramatik: area untuk bermain rumah-rumahan, bermain boneka, 'berdandan', bermain miniatur, bermain sandiwara, dan sebagainya

6. Zona lain-lain: untuk aktifitas bermain komputer, menonton TV/VCD, dan sebagainya

Penataan ruang dengan sistem zonasi, harus disesuaikan dengan sifat masing-masing zona. Menurut De Chiara (1980) dan Olds (2006), penempatan zona-zona tersebut adalah sebagai berikut:

1. Zona entry ditempatkan di dekat pintu masuk

2. Zona messy ditempatkan di dekat akses keluar ruangan atau di dekat zona entry. Pada zona ini sebaiknya terdapat bak cuci tangan dan meja/alas untuk permainan yang menggunakan air, pasir, dan tanah liat

3. Zona aktif diletakkan di dekat jalur sirkulasi uama ruangan. 
4. Zona tenang diletakkan di area yang terlindung, cukup terang, dan jauh dari zona entry.

Tahapan yang dilakukan dalam kegiatan ini adalah:

1. Mengevaluasi penggunaan ruang-ruang di kedua sekolah

2. Melakukan riset mengenai aplikasi metode pembelajaran (sesuai dengan kurikulum) kedua mitra terkait penggunaan ruang dan penataan perabot

3. Menyusun konsep desain penataan ruang kelas

\section{Hasil dan Pembahasan}

\subsection{Hasil Analisis}

Dari pengamatan dan analisis yang dilakukan, diketahui bahwa sekat non permanen mengurangi konsentrasi belajar anak-anak. Batas audio-visual-gerak yang non permanen tersebut menyebabkan terjadinya perembesan suara dan pandangan, serta memungkinkan gerakan anak-anak dari satu kelas ke kelas lainnya. Kelas ini merupakan ruang yang mendapat prioritas penanganan. Solusinya sebenarnya cukup mudah, yakni dengan membuat sekat ruangan secara permanen. Tetapi ruang ini ternyata juga digunakan un tuk tempat pertemuan. Untuk itu ruang ini harus didesain sebagai ruang multi-fungsi.

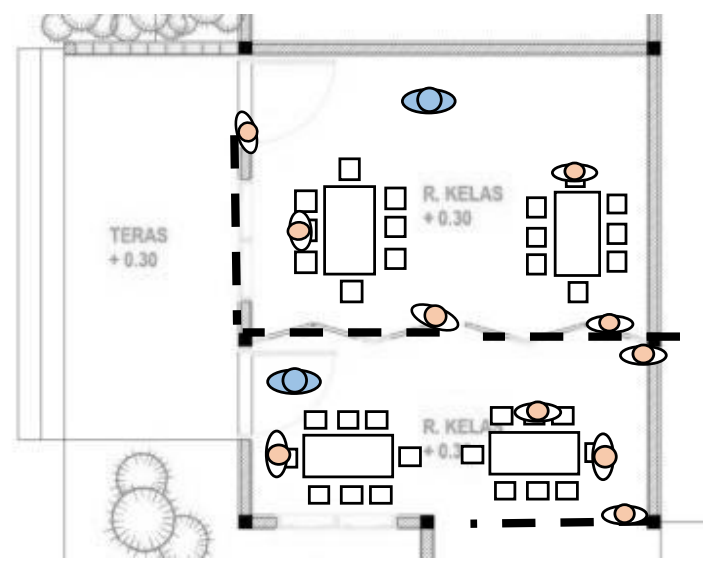

Keterangan:

os Guru

Murid
Gambar 6. Konfigurasi Ruang Memungkinkan untuk Mengintip Kelas Sebelahnya atau ke Ruang di Luar Kelas 


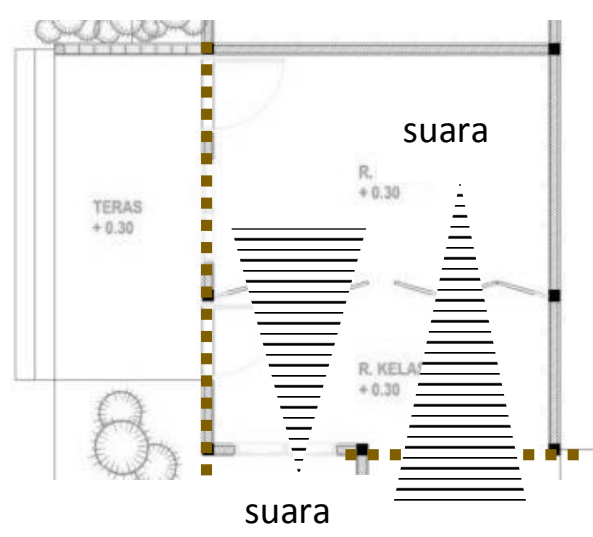

Gambar 7. Gangguan Suara Antar Kelas Sangat Mungkin Terjadi dan Mengganggu Konsentrasi Belajar
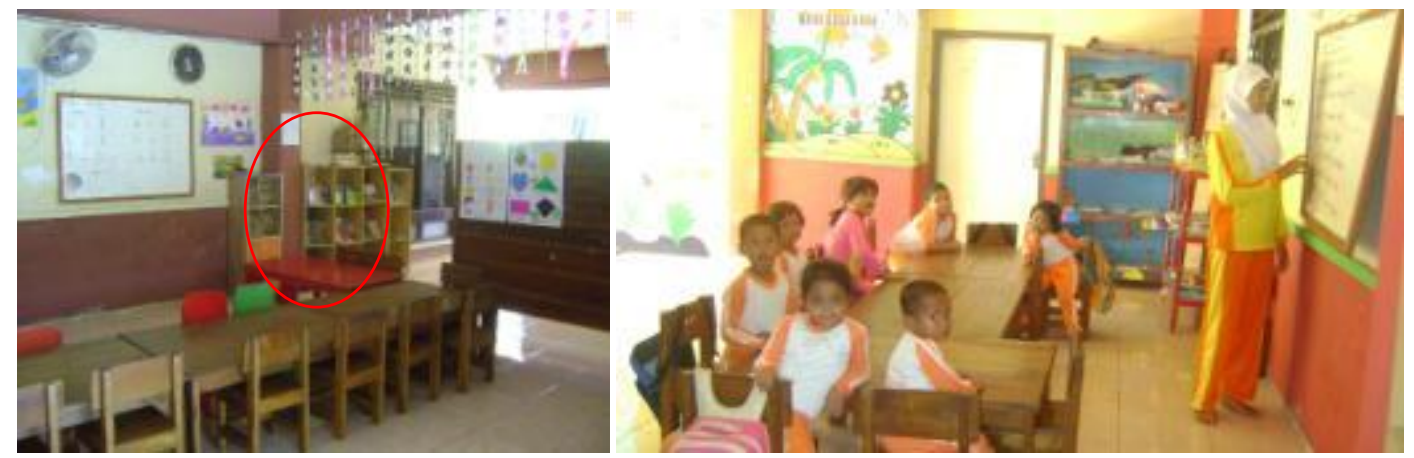

Gambar 8. Konfigurasi meja-kursi dan papan tulis menggangu pandangan anak karena silau dan bayangan dari pantulan bidang kaca dan dari halaman (karena tidak ada pembatas vertikal antara kelas dan teras/halaman)

Luas lahan yang terbatas menyulitkan pengembangan dan penataan ruang kelas PAUD Kuncup Matahari. Posisi kamar mandi/wc dan dapur (pantry) serta aksesibilitasnya tidak ideal karena melalui salah satu kelas.

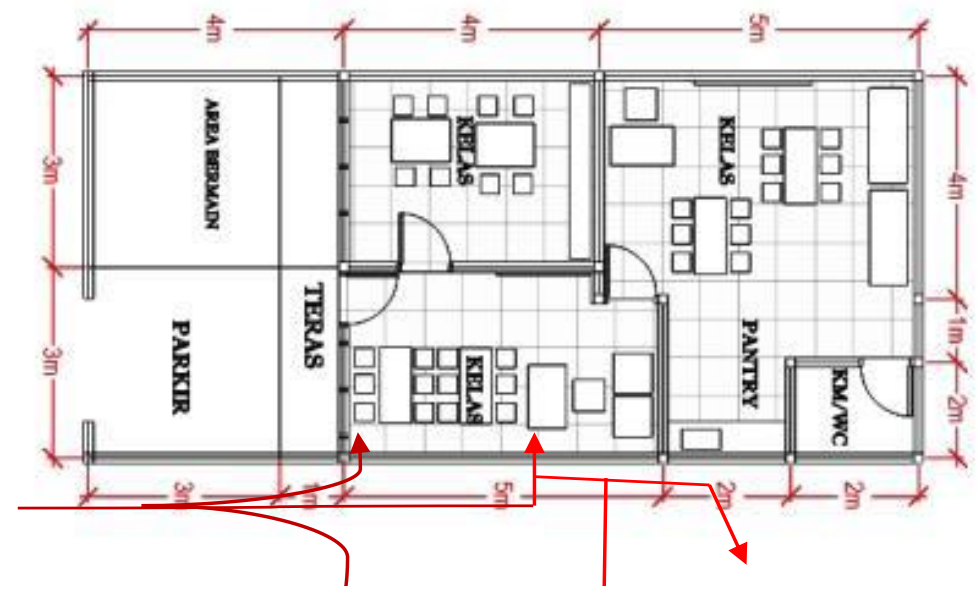

Gambar 9. Posisi ruang-ruang di PAUD Kuncup Matahari.

Akses menuju km/wc dan pantry serta ke kelas-kelas melalui salah satu kelas. 


\subsection{Rencana Tata Ruang}

Untuk kontrol audio-visual-gerak antar ruangan, serta untuk mewadahi kebutuhan ruang serbaguna, diperlukan sekat ruangan yang sekaligus juga sebagai rak penyimpan peralatan belajar. Sekat ini merupakan sekat non permanen, yang dapat dipindahpindahkan. Di bagian bawahnya dipasang roda untuk memmudahkan gerakannya, ditambah kaki yang dapat dilipat agar tidak mudah berpindah posisi pada saat dipasang sebagai sekat. Agar barang yang tersimpan lebih aman dan rak / sekat lebih awet, maka gerakan sekat dibatasi pada area tertentu dengan diberi engsel pada bagian yang menempel pada dinding. Antar rak diberi pengunci agar ketika dipasang sebagai sekat tidak mudah bergerak. Gambarannya adalah sebagai berikut:

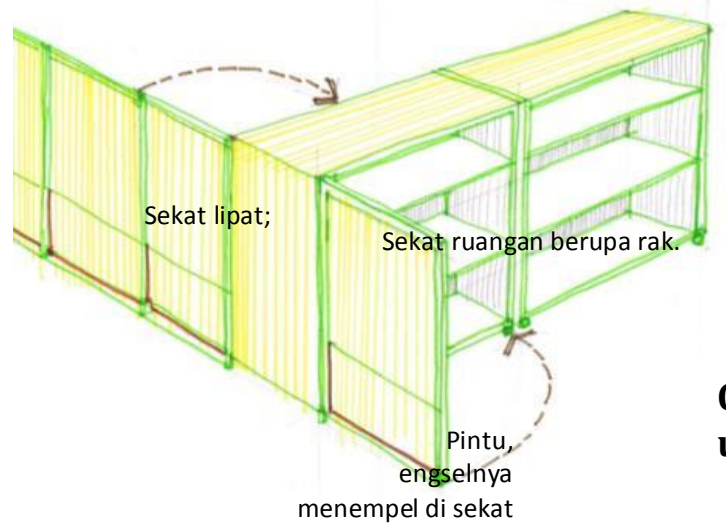

Gambar 10. Penyekat Ruang Multifungsi untuk Ruang Multifungsi

Penataan ruang kelas berbasis pada metode pembelajaran yang digunakan, yaitu metode sentra. Sentra-sentra dikelompokkan menurut beberapa zona, yaitu: zona entry, zona aktif, zona tenang, dan zona messy. Zona ini, selain dapat dibentuk menurut lokasi dan posisi ruang juga diatur atau dibentuk dengan cara mengatur waktu penggunaannya. Zona -zona ini menentukan letak sentra-sentra. Ada 7 sentra, yaitu: sentra persiapan (membangun kemampuan keaksaraan); sentra balok; sentra seni, sentra bahan alam; sentra peran kecil, sentra peran besar, dan sentra Iman dan Taqwa (agama). Setiap hari anak-anak bermain di sentra yang berbeda (moving class).

Model penataan ruang untuk di PG/RA Mutiara Bhima Sakti adalah sebagai berikut:

1. Optimalisasi halaman sebagai zona entry/persiapan dan zona aktif. Penggunaannya sebagai zona aktif dan zona entry diatur bergantian. Sebagai zona aktif, halaman dapat dijadikan ruang untuk sentra seni, dan sentra peran besar. Untuk itu perlu dilakukan pengaturan ruang pada halaman untuk parkir dan untuk kegiatan sekolah.

2. Optimalisasi halaman / kebun sebagai zona aktif dan zona messy. Kebun dapat dijadikan sentra Bahan alam. Di sini anak-anak dapat belajar menanam dan merawat tanaman (termasuk belajar tentang tanaman), dan bermain pasir/tanah.

3. Ruang kelas sebagai zona tenang. Ruang kelas dimanfaatkan untuk kegiatan yang membutuhkan konsentrasi tinggi. Misalnya sentra balok, sentra peran kecil, dan sentra persiapan. Sentra iman dan taqwa menggunakan ruang kelas besar yang multifungsi. Pada saat dipakai untuk sholat berjamaah, sekat antar ruangnya 
dibuka. Belajar membaca Al Qur'an / mengaji dilakukan per-kelas di dalam ruang kelas.

Contoh penataan interior kelas (diambil contoh beberapa sentra) dapat dilihat pada lampiran.

Untuk PAUD Kuncup Matahari model penataan ruang dilakukan sebagai upaya untuk:

1. Meminimalisir percampuran akses sehingga privasi ruang kelas lebih terjaga

2. Mendesain playground di bagian depan sebagai zona entry dan sekaligus zona aktif. Sebagai zona aktif, playground dimanfaatkan untuk sentra seni (drama, tari, lukis/gambar, dan musik).

3. Ruang Kelas A (kelas besar) sebagai untuk sentra iman dan taqwa (agama), sentra peran besar, dan sentra seni.

4. Ruang kelas B dan C untuk zona tenang (sentra balok, sentra peran kecil, dan sentra persiapan)

5. Desain interior 2 dan 3 dimensi disusun untuk sesuai dengan fungsi ruang menurut sistem sentra.

\section{Kesimpulan}

Dari kegiatan ini dapat disimpulkan bahwa penataan ruang kelas untuk kedua kasus terutama berkaitan dengan penataan perabot, pembatas ruang, pembagian ruang sesuai zona, dan penggunaan ruang untuk zona-yang berbeda dapat diatur dengan pengaturan jadwal kegiatan.

\section{Ucapan Terima Kasih}

Ucapan terima kasih disampaikan kepada DIKTI yang telah mendanai kegiatan ini melalui program IbM 2013 dan pihak LPPM Universitas Brawijaya yang telah memfasilitasi kegiatan ini.

\section{Daftar Pustaka}

De Chiara, J. \& Callender, J.H. 1980. Time Saver Standarts for Building Types. New York: Mc Graw-Hill Inc.

Direktorat Pendidikan Anak Usia Dini. 2002. Acuan Menu Pembelajaran pada Pendidikan Anak Usia Dini (Menu Pembelajaran Generik). Jakarta: Direktorat Pendidikan Anak Usia Dini.

Direktorat Pendidikan Anak Usia Dini. 2006. Pedoman Penerapan Pendekatan "Beyond Centres and Circle Time (BCCT)" (Pendekatan Sentra dan Lingkaran) dalam Pendidikan Anak Usia Dini. Jakarta: Direktorat Pendidikan Anak Usia Dini.

Olds, A.R. 2001. Child Care Design Guide. New York: The Mc Graw Hill Companies

Olds, A.R. 2006. Spaces Room Layout for Early Childhood Education. New York: Community Products, LLC

Satyawadaningtyas, Apsari. 2009. Keterkaitan Tata Letak Perangkat Bermain di Ruang Kelas Kelompok Bermain terhadap Perilaku Bermain Anak. Skripsi. Jurusan Arsitektur Fakultas Teknik Universitas Brawijaya. Unpublished 


\section{Lampiran}

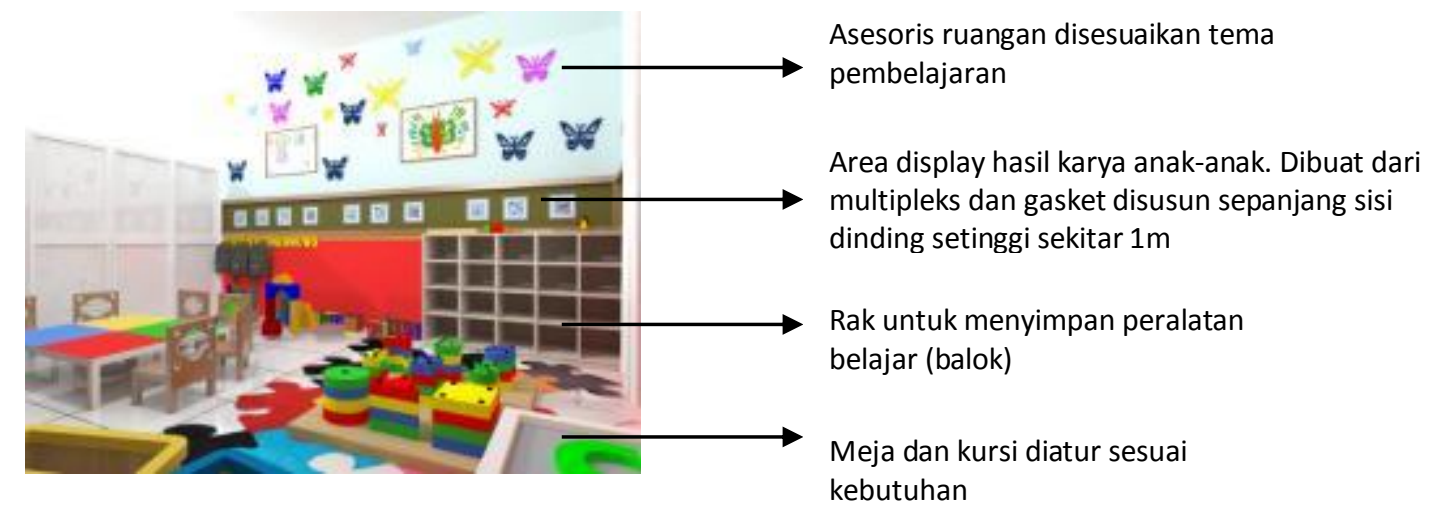

Gambar 1. Penataan Ruang Sentra Balok

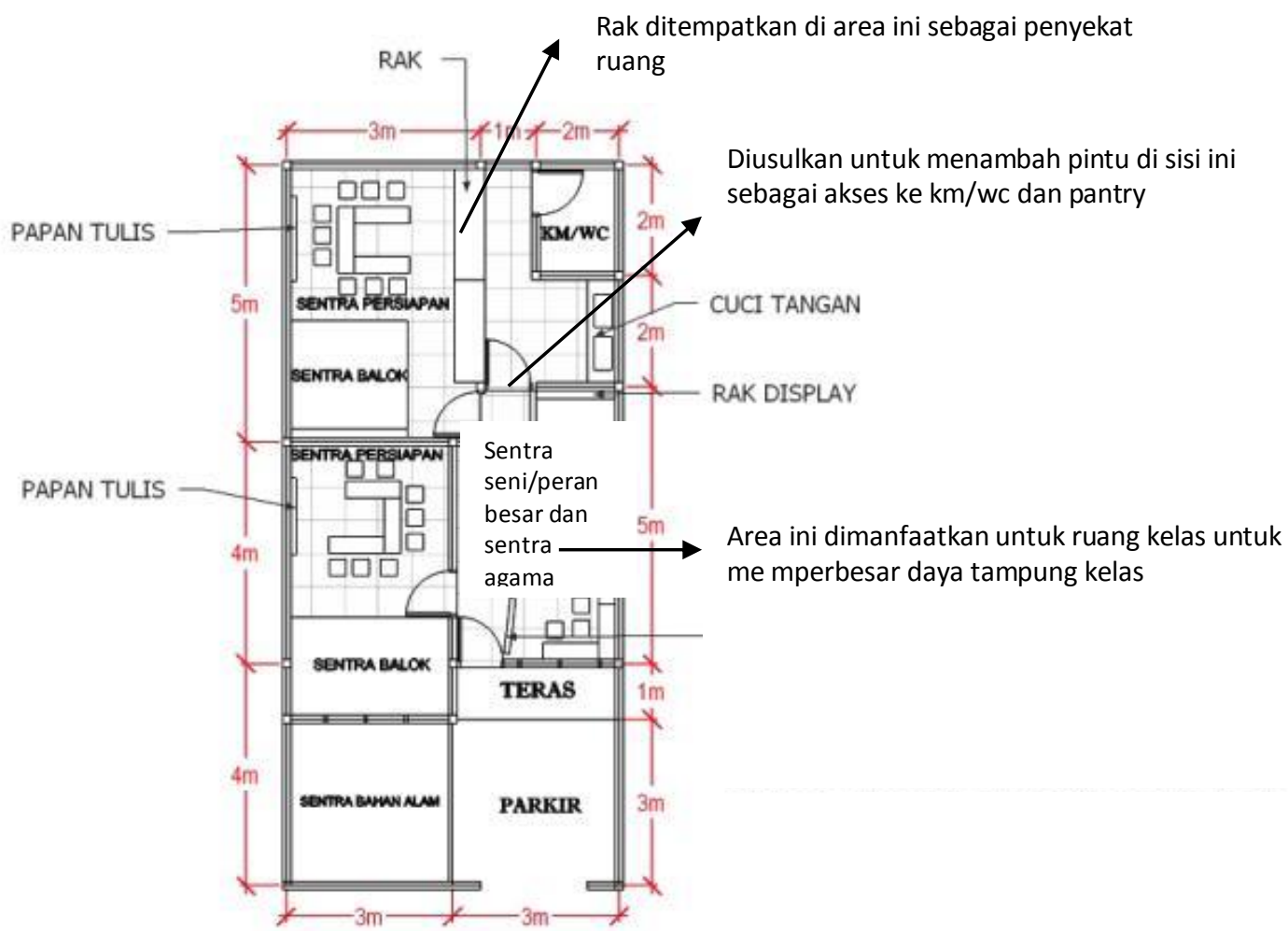

Gambar 2. Lay-out Penataan Ruang PAUD Kuncup Matahari 


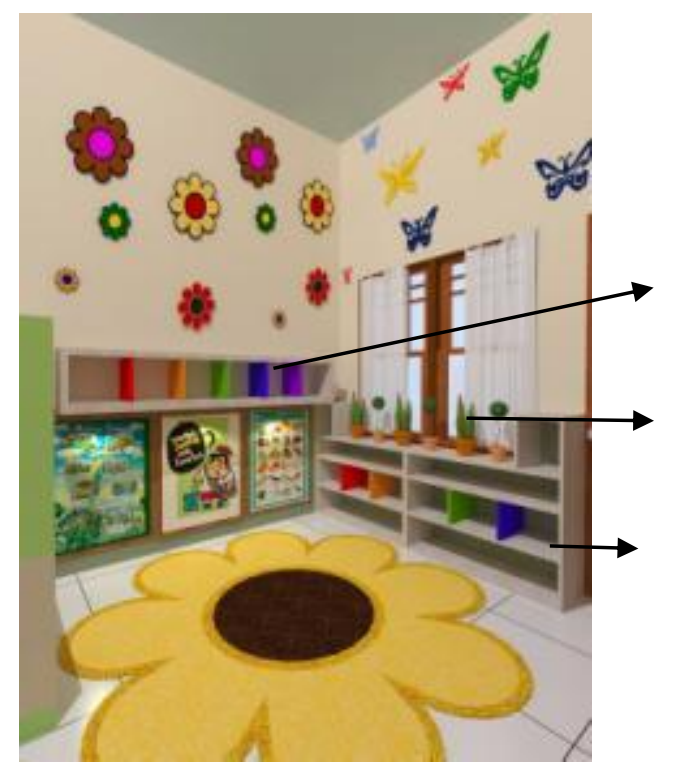

Rak gantung di dinding, agar ruang lebih efektif

Tanaman kecil-kecil di dalam ruangan untuk menambah 'zona hijau'

Rak pendek yang terjangkau anak-anak untuk menyimpan peralatan belajar

Gambar 3. Contoh Gambar Penataan Ruang Kelas PAUD Kuncup Matahari

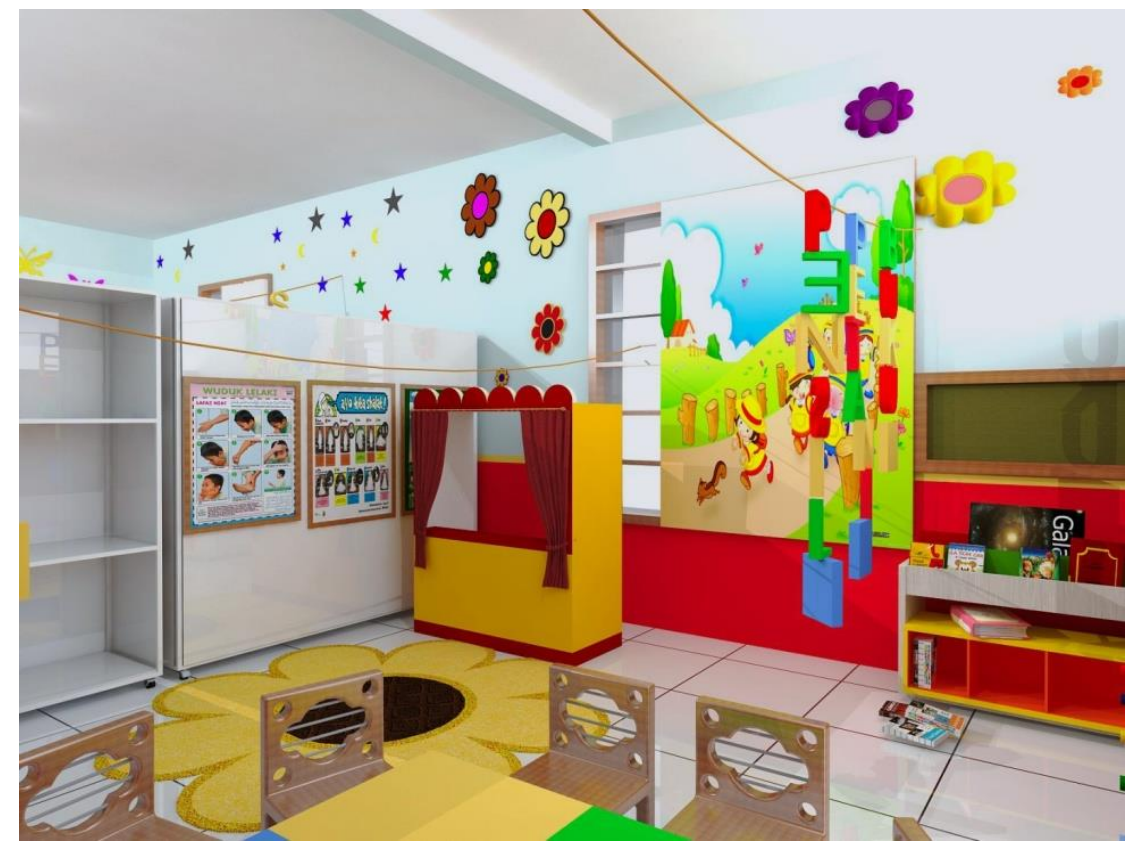

Gambar 4. Sentra Dramatik PG/RA Mutiara Bhima Sakti 